\title{
Antibacterial and Chemical Properties of Chromatographic Fractions of Acidic Metabolites from Garcinia Kola Seed Extract
}

\author{
Ogbuneke Romanus Uka ${ }^{1}$, Okoroiwu C. C. ${ }^{2}$, Onu Uchenna L. ${ }^{2}$, Onyeocha U. ${ }^{2}$, Ejele A. E. ${ }^{2}$ \\ ${ }^{1}$ Department of Chemistry, Alvan Ikoku Federal College of Education, Owerri, Imo State Nigeria, Nigeria \\ ${ }^{2}$ Department of Chemistry, Federal University of Technology, Owerri, Imo State, Nigeria \\ Correspondence: Ogbuneke Romanus Uka, Department of Chemistry, Alvan Ikoku Federal College of Education, \\ Owerri, Imo State Nigeria, Nigeria. E-mail: rogbuneke@yahoo.com, Tel: +2348037091181
}

Received: March 5, 2015 Accepted: March 19, 2015 Online Published: August 14, 2015

doi:10.5539/ijc.v7n2p68 URL: http://dx.doi.org/10.5539/ijc.v7n2p68

\begin{abstract}
Acidic metabolites were precipitated from ethanolic extract of Garcinia kola seed and fractionated by column chromatography to obtain three fractions AM1, AM2, and AM3. Chemical test on the acidic metabolites and the fractions showed they were mainly flavonoids. In vitro antibacterial screening of the fractions showed they possessed antibacterial activity. They inhibited the growth of five human test bacterial isolates: Coliform bacilli, Escherichia coli, Salmonella spp., Staphylococcus aureus and Streptococcus spp. Their inhibition zone diameters ranged from $8 \mathrm{~mm}$ to $26 \mathrm{~mm}$. The standard control antibiotic Ciprofloxacin gave inhibition zone diameters ranging from $18 \mathrm{~mm}$ to $20 \mathrm{~mm}$, at the same concentration of $100 \mathrm{mg} / \mathrm{ml}$ for the same test bacteria. It was concluded that with appropriate standardization, the three fractions from the acidic metabolites of ethanolic extract of seed of Garcinia kola could effectively complement the existing antibiotics with beneficial health effect.
\end{abstract}

Keywords: Acidic Metabolites, Bacterial Isolates, Inhibition Zone Diameter, Ciprofloxacin

\section{Introduction}

Garcinia kola commonly known as "bitter kola-", is a medium sized plant that may grow up to 15 to 25 meter high with a girth of about 6 centimeter. G. kola an angiospermea, belongs to the family Guttiferaea and is widely distributed in the tropical wetland region of Central and West Africa (Keay, 1989; Uko, Usman \& Ataja 2001). The plant has been described as a "magic plant", because every part of it has been found to be medicinally useful (Dalziel, 1937). The seeds are smooth, elliptical in shape, covered by a thin brown seed coat and composed of light yellow to cream coloured pulp. The seeds are served with or without other kolas in homes, cultural and social functions for traditional African hospitality. The seeds are masticulatory and leave astringent bitter taste given the synonym "bitter kola" (Isawumi, 1993).

Ethnopharmacological investigation of extracts of various parts of the plant have demonstrated their use for the relief and treatment of laryngitis, mouth infections, cough, heart burn, liver disorder, chest cold, colic, headache and inflammatory diseases (Anislce, 1937 \&, Ayensu, 1978; Iwu, 1982). The seed has also been shown to be useful as bronchodilator and antimicrobial in the treatment of bronchitis, throat troubles, heart diseases and urinary tract infections (Irvine, 1961; Iwu, 1985, 1986, 1993; Iwu, Igboko, Elekwa \& Tempesta, 1990). Ebana, Madunagu, Ekpe and Otung (1991) investigated the antimicrobial, antibacterial and antiviral properties while Iwu (1999) stated that Garcinia kola seed can be used as adaptogen and anti-inflammatory agent as well as in the cure of flu and influenza. Nwankwo,Tahakenga and Emerole (2000) and Okwu (2005) showed that Garcinia kola can as well be useful in the treatment of cirrhosis and hepatitis. In addition to the medicinal use Garcinia kola seed has been reported as a good alternative to hops in the brewing of larger beer (Aniche \& Uwakwe, 1990; Ogu \& Agu, 1995).

In recent years, there has been an increasing interest in the bioavalability and biological activity of secondary metabolites of plants. This is because many infectious micro-organisms have become resistant to some existing drugs, the global problems of multiple antibiotic resistance as well as emergence of new resurrection of previously eradicated diseases (Adegboye, Akinpelu \& Okoh, 2008). Efforts as such have generated an amazing analytical results and data. Recent studies have confirmed that Garcinia kola seed extracts possess antimicrobial effects and inhibit the growth of micro-organisms that may be bacterial, fungal,, viral as well as possess 
antioxidant properties (Ejele, 2010; Ejele \& Akujobi 2011; Ejele, Nwaeze \& Alinnor 2012a, Arekemase, et. al, 2012; Daramola, Adegoke \& Osonyinlusi,, 2012; A. Ukaoma, V. Ukaoma Okechukwu \& Iwuagwu, 2013).

In another study, Ejele, Iwu, Enenebeaku, Ukiwe and Okolue (2012b) effected a bioassay guided isolation, purification and partial characterization of chromatographically purified antimicrobial compounds from basic metabolites of Garcinia kola and indicated that the basic metabolite contains phenolics such as catechin p-naphtholbenzein, $\alpha$ - methyl-dl-tyrosine or naringin.

In this context, we report the antibacterial and chemical properties of fractions obtained in the chromatographic fractionation of the acidic metabolites isolated from the ethanol extract of seeds of Garcinia kola.

\section{Materials and Method}

\subsection{Plant Material}

Fresh seeds of Garcinia kola were purchased from Ekeonuwa, Owerri, Imo State, Nigeria. The brown seed coat was removed and the seeds thoroughly washed with distilled water, cut into small pieces and ground into a fine meal in a hand blender. The meal was spread out to dry at room temperature under the fan for a couple of days.

\subsubsection{Extraction of Plant Material}

$50 \mathrm{~g}$ of the dry pulverized plant material was put into a soxhlet extractor and extracted with $250 \mathrm{ml}, 95 \%$ ethanol for eight hours. The extract was allowed to cool down, filtered and then the solvent allowed to evaporate at room temperature to a gel. The gel was dissolved in ethanol: water (4:1) mixture and filtered. The filtrate (extract) was used without further treatment for the preparation of the acidic metabolites (Ejele \& Alinnor, 2010).

\subsection{Preparation of Acidic Metabolites (Flavonoid-1)}

The acidic metabolites were prepared according to the literature Ejele et al (2012a). $30 \mathrm{ml}$ of the filtrate obtained above was treated with $15 \mathrm{ml}$ of $2 \mathrm{M} \mathrm{HCl}$ and extracted with $30 \mathrm{ml}$ of chloroform in a separating funnel. The mixture was shaken vigorously with occasional release of pressure; the mixture was allowed to stand overnight. Two layers were formed; the upper aqueous $\mathrm{HCl}$ layer was discarded. The lower chloroform layer was taken in another funnel and treated with $2 \mathrm{M} \mathrm{NaOH}$ solution. The mixture was shaken as before and the mixture allowed to stand overnight. Two layers were again formed; the lower chloroform layer was removed and the aqueous alkaline layer was treated with $50 \% \mathrm{H}_{2} \mathrm{SO}_{4}$ drop after drop until the solution became acidic and a black precipitate (Flavonoid -1) (F1) was formed, then F1 was washed with distilled water and allowed to dry in air at room temperature.

\subsubsection{Purification of Flavonoid -1}

A portion of the acidic metabolites (Flavonoid -1) was dissolved in a minimum volume of $2 \mathrm{M} \mathrm{NaOH}$ solution and then precipitated with $50 \% \mathrm{H}_{2} \mathrm{SO}_{4}$. The mixture was put in the separating funnel and double the volume of chloroform added, and the mixture shaken vigorously as described in 2.2 and then was allowed to equilibrate. The chloroform layer was removed through a Whatman No 1 filter paper and the reddish-brown precipitate obtained, collected through the same filter paper, washed with distilled water and allowed to dry in air at room temperature and collected as Flavonoid - 2 (F2).

\subsection{Chromatographic Fractionation/Separation of Flavonoid-2}

The Flavonoid - 2 (F2) was fractionated in a chromatographic column. A slurry of finely powered silica gel (in chloroform) was packed in a glass column to a height of $25 \mathrm{~cm}$. The column was loaded with about $10 \mathrm{ml}$ of F2 dissolved in ethanol. The column was eluted by gradient elution starting with chloroform/ethanol mixture (1:1), (1:2) and finally $95 \%$ ethanol. The elute were collected in test tubes at 30 minutes intervals. The elutes collected were bulked on similarity of colour. Three fractions were collected: AM1, AM2, and AM3 and were screened for antibacterial activity.

\subsection{Chemical Tests on the Fractions.}

Each of the fractions was tested with the following: dilute $\mathrm{NaOH}$ solution, dilute $\mathrm{Na}_{2} \mathrm{CO}_{3}$ solution and $\mathrm{FeCl}_{3}$ solution for phenolic functional groups and aqueous $\mathrm{NaHCO}_{3}$ for carboxylic acids.

\subsection{Antibacterial Screening of the Isolates}

The crude extract (CE); Flavonoid - I (F1) Flavonoid - 2 (F2) and the fractions AM1, AM2 and AM3 and the control antibiotic ciprofloxacin were subjected to antibacterial screening test at the Department of Microbiology, Federal Medical Centre, Owerri, Nigeria. The test was carried out using the Agar Disk Diffusion method described by Willey, Sherwood and Woolverton (2008). An inoculation loop or needle was touched to four or five isolated colonies of the pathogen growing on agar and then used to inculcate a tube of culture broth and the 
culture incubated for a few hours at $35-37^{\circ} \mathrm{C}$ until it became slightly turbid. It was then diluted to match a turbidity standard. Then a sterile cotton swab was dipped into the standard bacterial test suspension and used to evenly inoculate the entire surface of an agar plate. The inoculated agar plat was allowed to stand for five minutes to allow proper diffusion and reasonable drying, then the appropriate antibiotic test disks were placed on it with a multiple applicator device and the plate was immediately placed in an incubator maintained at $35-37^{\circ} \mathrm{C}$. After 16-18 hours incubation, the diameters of the zones of inhibition were measured to the nearest $\mathrm{mm}$.

\section{Results and Discussions}

The chemical tests on the fractions indicate that they are polyphenols of the Flevanoid group and they are not carboxylic acids as shown in table 1.

Table 1. Results of Chemical Tests with Fractions

\begin{tabular}{ll}
\hline Dilute $\mathrm{NaOH}$ solution & Dissolved freely \\
\hline Dilute $\mathrm{Na}_{2} \mathrm{CO}_{3}$ solution & Insoluble \\
Dilute $\mathrm{NaHCO}_{3}$ solution & No effervescence \\
$\mathrm{FeCl}_{3}$ solution & Reddish-brown to violet precipitate \\
\hline
\end{tabular}

The results of the antibacterial activities of the crude extract (CE), Flavonoid -1 (F1), Flavanoid-2 (F2) and the three chromatographic fractions identified as AM1, AM2 and AM3 together with the control antibiotic Ciprofloxacin ; against the five test bacterial isolates, Coliform bacilli, Escherichia Coli, Salmonella Spp, Staphylococcus aureus and Streptococcus Spp at $100 \mathrm{mg} / \mathrm{ml}$ are presented in table 2

Table 2. Antibacterial potential of various fractions

\begin{tabular}{llllllll}
\hline Bacteria Isolate & \multicolumn{7}{l}{ Inhibition Zone Diameter in mm } \\
\hline & CE & F1 & F2 & AM1 & AM2 & AM3 & Ciprofloxacin \\
Coliform bacilli & 0 & 15 & 25 & 12 & 22 & 25 & 20 \\
Escherichia coli & 0 & 15 & 22 & 12 & 20 & 15 & 18 \\
Salmonella spp & 0 & 13 & 25 & 8 & 20 & 17 & 20 \\
Staphylococcus aureus & 0 & 18 & 25 & 26 & 22 & 17 & 20 \\
Streptococcus spp & 0 & 18 & 20 & 18 & 25 & 25 & 19 \\
\hline
\end{tabular}

All test bacterial isolates were not susceptible to the crude extract at stated concentration. Coliform bacilli, Escherichia coli and Salmonella spp were not susceptible to F1 and AM1 however AM 1 had the highest zone of inhibition diameter against Staphylococcus aureus which was $26 \mathrm{~mm}$. The inhibition zone diameters of the acidic metabolites and its fractions ranged from 8 to $26 \mathrm{~mm}$ while those of the control drug Ciproxfloxacin ranged from 18 to $20 \mathrm{~mm}$. F2, AM2 and AM3 with inhibition zone diameters $25 \mathrm{~mm}, 22 \mathrm{~mm}$ and $25 \mathrm{~mm}$ compared favorably with the control antibiotic Ciprofloxacin $(20 \mathrm{~mm})$ against Coliform bacilli. F1 was found to be a weak antibacterial agent at the stated concentration, while none of the fractions and even the control antibiotic equaled or superseded F2 in action against Salmonella Spp. The antibiotic activity of F2 against Salmonella Spp can thus be attributed to synergistic action of the fractions.

The crude extract (CE) had no activity on all the bacterial isolates tested, however Adegboye et al (2008) observed this in respect of Staphylococcus aureus (NCIB 858) which was not susceptible to a $20 \mathrm{mg} / \mathrm{ml}$ Garcinia kola extract from a 3:2 methanol and sterile distilled water mixture extracting solvent but on the contrary observed that Streptococcus faecalis had an inhibition zone diameter of $10 \mathrm{~mm}$; Eschericia coli $22 \mathrm{~mm}$. In a similar study, Akinpelu, Adegboye, Adeloye and Okoh (2008) carried out a partial purification by fractionation using various solvents of varying polarity, viz: n-hexane, n-butanol, diethylether, chloroform, and observed that Escherichia coli was sensitive to two fractions at $10 \mathrm{mg} / \mathrm{ml}$, which are n-butanol $(21 \mathrm{~mm})$ and diethyleher fraction (18mm). On the other hand Staphylococcus aurous (NCIB) was not susceptible to any of the fractions. Ukaoma et al (2012) reported that the crude ethanol extract showed zones of inhibition diameter for Staphylococcus aureus as $19.5 \mathrm{~mm}$ and Eschericia coli $15 \mathrm{~mm}$. These results are in tandem with F1 and F2 in this work.

In a previous paper, Ejele et al (2012a) reported the antimicrobial potential of crude phenolic ]isolates from Garcinia kola stating the inhibition zone diameters for the reddish-brown precipitate( F1) as: Staphylococcus aureus $10 \mathrm{~mm}$, Streptococcus spp. $10 \mathrm{~mm}$, Coliform bacilli $11 \mathrm{~mm}$, Escherichia coli 20mm. These results deviated from the observation in this report where the inhibition zone diameters are as follows F1 $18 \mathrm{~mm}$. and F2 $25 \mathrm{~mm}$ for Staphylococcus ; F1 $18 \mathrm{~mm}$ and F2 $20 \mathrm{~mm}$ for Streptococcus ; F1 $15 \mathrm{~mm}$ and F2 $25 \mathrm{~mm}$ for Coliform; F1 $15 \mathrm{~mm}$ and F2 $22 \mathrm{~mm}$ for Escherichia; respectively. 
Differences in results may arise from various factors such as differences in preparation of plant material, the extraction solvents, as well the source of plant material and other environmental factors.

\section{Conclusion}

The antibacterial properties of acidic metabolites and the chromatographic fractions were assessed. The results show that Flavonoid-2 and its fractions have promise as a source of potential antibiotic agent. Plant based antimicrobials are said to have enormous therapeutic potential, as they can serve the needed purposes with less side effect that are often associated with synthetic antimicrobials (Iwu, Duncan \& Okunji, 1999). The findings in this work are a good foundation for further characterization for structural elucidation of the flavonoid antibacterial components of Garcinia koka seeds which is a subject of ongoing studies of our research team.

\section{Recommendation}

A lot of phytochemicals had been reported by various workers (Adegboye et. al 2008; Adesuyi et al 2012; etc). It is recommended that efforts be expended in investigating the medicinal properties of each of the constituent chemicals of Garcinia kola, as the identification of the active constituents is important for assessing these in vivo.

\section{References}

Adegboye, M. F., Akimpelu D. A., \& Okoh, A. L. (2008). The Bioactive and Phytochemical Properties of Garcima kola (Heckel) Seed Extract on s Some Pathogens. Afri. J. Biotechnol, 7, 3934-3938.

Adesuyi, A. O., Elumm, I. K., Adaramola, F. B., \& Nwokeocha, A. G. M. (2012). Nutritional and Phytochemical Screening of Garcinia kola. Advanced Journal of Food Sci. and Technology, 4(1), 9-14.

Akinpelu, D. A., Adegboye, M. F., \& Okoh, A. I. (2008). Biocidal Activity of Partially Purified Fractions from m

Aniche, G. N., \& Uwakwe G. U. (1990). Potential Use of Garcima as Hops Susbtitte in Large Beer Brewing. World J. Microb, Biotechnol. 6, 323-327. http://dx.doi.org/10.1007/BF01201305

Anislie J. R. (1937). Plants used in native medicine in Nigeria. Imperial Forestry Institute. Oxford, 42.

Arekemase, M. O., Aliyu, M. B., Kayodi, R., Ojo, M., Ajiboyo, A. E., \& Ajinkakew, A. K. (2012). Antimicrobial Effects of Garcima kola (Bitter kola) on Some Selected Pathogens from University of Ilorin Teaching Hospital. Ilorin, Nigeria. Journal of Asian Scientific Research, 2(4), 159-169.

Ayensu, E. S. (1978). Medicinal plants of West Africa. Reference Publ. Inc. Algonac, Michigan. 162.

Dalziel, J. M. (1937). The useful plants of West Tropical Africa. Crown Agents for the Colonies. London.

Daramola, B., Adegoke, O. G., \& Osonyinlusi, S. A. (2012). Antioxidant Activities of Garcinia kola Seed: Fractionation and Assessment of Antioxidant Activities of Active Components of Garcinia kola Seed. Mycotoxines. Technical article.

Ebana, R. U., Madunagu, B. F., Ekpe, E. D., \& Otung, I. N. (1991). Microbiological Exploitation of Cardiac Glycosides and Alkaloids from Garcima kola, Boneria ocymoides, Kola nitida and Citrus aurantafolia. J. Appl. Bacteriol., 71(5), 398 - 401. http://dx.doi.org/10.1111/j.1365-2672.1991.tb03807.x

Ejele, A. E, Nweze, A. E., \& Alinnor, J. I. (2012). Comparison of Antimicrobial Potential of Crude Phenolic Isolates from Garcinia kola. Inter. Research J. of Biotechnology, 3(2), 61 - 64

Ejele, A. E. (2010). Effects of Some Plant Extracts on the Microbial Spoilage of Cajanus cajan.. International Journal of Tropical Agriculture and Food System, 4(1), 46 - 49

Ejele, A. E., \& Akujobi, C. O. (2011). Effects of Secondary Metabolites of Garcini kola on the Microbial Spoilage of Cajanus cajan Extract. Int. J. Trop. Agric. Food System, 5(1), 8 - 14.

Ejele, A. E., \& Alinnor, J. I. (2010). Anti-sickling Potentials of Aloe vera Extract, IV: Effects of Acidic, Basic and

Ejele, A. E., Iwu, I. C., Enenebeaku, C. K., Ukiwe, L. N., \& Okolue, B. N. (2012). Bioassay Guided Isolation, Purification and Characterization of Antimicrobial Compounds from Basic Metabolites of Garcinia kola. Journal of Emerging Trends in Engineering and Applied Sciences (JETEAS). 3(4), 668-672.

Irvine, F. R. (1961). Woody plants of Ghana with special references to the uses. Oxford University Press. London. $145-148$.

Isawumi, A. M. (1993). The common edible fruits of Nigeria. Part II. The Nigerian Field. 59, 1-2.

Iwu, M. M. (1985). Antihapatoxic Constituents of Garcinia kola seeds. Experientia. 41, 699-670. 
http://dx.doi.org/10.1007/BF02007729

Iwu, M. M. (1993). Handbook of African Medicinal Plants. Boca. Raton CRC Press Inc. 223 - 224.

Iwu, M. M. (1982). Traditional Igbo Medicine. Institute of African Studies. University of Nigeria, Nsukka, 104.

Iwu, M. M. (1986). Plant flavonoids in biology and medicine. Ala R, Lisa, New York.

Iwu, M. M., Duncan, A. B., \& Okunji, C. O. (1991). New antimicrobials of plant origin in Janick J. (ed): Perspective of new crops and new uses. Alexandria. ASHA Press, 457-462.

Iwu, M. M., Igbokao, O. A., Elekwa, O. K., \& Tempesta, M. S. (1990). Prevention of Thioacetamide - induced Hepatotoxicity by Bioflavonoids of Garcinia kola. Phytotherapy Research, 4(4), 157-159. http://dx.doi.org/10.1002/ptr.2650040407

Keay, R. W. J. (1989). Trees of Nigeria: Revised version of Nigerian Trees (1964). 1-2. Clarendon Press, Oxford. $291 \mathrm{p}$

Methanolic Extract of Garcinia kola (Heckel) Seeds on Bacterial Isolates. Biol. Research, 41, $277-287$. http://dx.doi.org/10.4067/S0716-97602008000300005

Neutral Metabolites on Gellng and Sickling of H uman HbSS Erythrocytes. International Journal of Natural and Applied Sciences, 6(2), 155 - 160.

Nwankwo, J. O, Tahakenga, D. O., \& Emerole, G. O. (2000). Inhibition of Aflatoxin Bi- Genotoxicity in Human Liver Derived Hep G2 Cells by Kolaviron Biflavonoids and Molecular Mechanism of Action. Eur. J. Cancer Prevention, 9, 351 - 361. http://dx.doi.org/10.1097/00008469-200010000-00010

Ogu, E. O., \& Agu, R. C. (1995). A Comparison of Some Chemical Properties of Garcinia kola and Hops for Assessment of $\underline{\text { Garcinia }}$ Brewing Value. Bioresour. Technol,. 54, 1-4. http://dx.doi.org/10.1016/0960-8524(95)00081-X

Okwu, D. E. (2005). Phytochemicals: Vitamins and Mineral Contents of Two Nigerian Medicinal Plants. Int. J. Med. Adv. Sci., 1, 375-381.

Ukaoma, A. A., Ukaoma, V. O., Okechukwu, R. I., \& Iwuagwu, M. (2013). Phytochemical Screening and Antibacterial Properties of Garcinia kola. The journal of Phytopharmacology, 2(3), 34-38.

Uko, O. J., Usman, A., \& Ataja, A. M. (2001). Some Biological Activities of Garcinia kola in Growing Rats. Veterinski Arhiv., 71, 287 - 297.

Willey, J. M., Sherwood, L. M., \& Wollverton, C. J. (2008). In Prescott, Harley and Klein's Microbiology (7 ${ }^{\text {th }}$ ed) Mc.Grawhill International Edition. New York USA, 841-842.

\section{Copyrights}

Copyright for this article is retained by the author(s), with first publication rights granted to the journal.

This is an open-access article distributed under the terms and conditions of the Creative Commons Attribution license (http://creativecommons.org/licenses/by/3.0/). 